http://journal.unj.ac.id/unj/index.php/jpud

Volume 12 Edisi 2 November 2018

JURNAL PENDIDIKAN USIA DINI

DOI: https://doi.org/10.21009/JPUD.122

DOI: https://doi.org/10.21009/JPUD.122.18

\title{
UNIT STUDIES CURRICULUM: STRATEGI GURU DALAM IMPLEMENTASI KURIKULUM DI JUNGLE SCHOOL SIDOMUKTI
}

\author{
Yunita Iriani Kawaitouw ${ }^{1}$, Ajeng Ayu Widiastuti' ${ }^{2}$, Mozes Kurniawan ${ }^{3}$ \\ PG PAUD, FKIP, Universitas Kristen Satya Wacana Salatiga \\ E-mail:27204108@student.uksw.edu ${ }^{1}$, ajeng.widiastuti@staff.uksw.edu ${ }^{2}$ \\ mozes.kurniawan@staff.uksw.edu3
}

\begin{abstract}
ABSTRAK
This observation is purposed to know the teacher's strategy in implementing Unit Studies Curriculum. The type of this observation is a qualitative observation that would be held in 4 months through direct participation in the classroom from the beginning till the end of the activity. Subjects of the observation are 5 teachers which there are 4 preschool teachers and 1 kindergarten teacher in detail. The data gathering techniques is using a semi-structured interview, observation, and documentation. Used observation instrument is throught the interview questions according to the topics that are about to be observed. Used data analysis technique is a descriptive qualitative one. The results of this study indicate that the teacher's strategy in implementing the Unit Studies curriculum at Jungle School is run through interesting and creative play activities, and with games such as touch and tell games, matching games, exercise games, opposite games, paper telephone cups and several games. others that are different every day.
\end{abstract}

Keywords: Learning Strategies, Unit Studies Curriculum, A Method of Play.

Penelitian ini bertujuan untuk mengetahui strategi guru dalam mengimplementasikan Unit Studies Curriculum. Jenis penelitian ini adalah penelitian kualitatif yang dilaksanakan selama 4 bulan melalui partisipasi langsung di dalam kelas dari awal kegiatan berlangsung hingga kegiatan berakhir. Subjek penelitian berjumlah 5 orang guru dengan rincian 4 orang guru preschool dan 1 orang guru kindergarten. Teknik pengumpulan data menggunakan wawancara semiterstruktur, observasi, dan dokumentasi. Instrumen penelitian yang digunakan melalui pertanyaan-pertanyaan wawancara sesuai dengan topik-topik yang ingin diteliti. Teknik analisis data yang digunakan adalah deskriptif kualitatif. Hasil penelitian ini menunjukkan bahwa strategi guru dalam mengimplementasikan kurikulum Unit Studies di Jungle School dijalankan melalui kegiatan bermain yang dibuat dengan menarik dan kreatif, dan dengan games seperti touch and tell game, matching game, exercise game, opposite game, paper cup telephone dan beberapa game lainnya yang berbeda setiap harinya.

Kata Kunci: Strategi Pembelajaran, Unit Studies Curriculum, Metode Bermain

\section{PENDAHULUAN}

Kurikulum ialah sejumlah mata pelajaran yang ditempuh dan di pelajari untuk memperoleh pengetahuan. Kurikulum diartikan program pembelajaran serta pengalaman belajar yang disediakan sekolah melalui kegiatan-kegiatan secara sistematis untuk membantu pertumbuhan, perkembangan dan sosial siswa (Winarso, 2017).

Dalam jenjang Pendidikan Anak Usia Dini, terdapat juga kurikulum 
yang menjadi acuan dalam pelaksanaan proses belajar dan bermain untuk mencapai tujuan pertumbuhan dan perkembangan anak yang optimal. Kurikulum yang pernah dikembangkan dan diberlakukan pada jenjang PAUD di Indonesia adalah Kurikulum 2013 PAUD, Kurikulum Berbasis Kompetensi. Menurut Bestdone (dalam Cholimah, 2012) pengembangan kurikulum harus dikuasai oleh setiap guru tanpa terkecuali, jika guru gagal dalam mengembangkan kurikulum maka ia gagal dalam kerjanya. Pengembangan kurikulum itu sendiri merupakan bagian yang esensial dari pada program pendidikan.

Pada umumnya sekolah PAUD di Salatiga menggunakan kurikulum 2013 PAUD sebagai kurikulum utama. Di Salatiga terdapat sekolah yang tidak menggunakan kurikulum 2013, sekolah ini menggunakan kurikulum sendiri yang disebut Unit Studies untuk diaplikasikan dalam kegiatan proses belajar mengajar di Jungle School. Proses pembelajaran di Jungle School memanfaatkan benda-benda sekitar alam seperti ranting pohon, daun-daun dan games yang menarik.

\section{KAJIAN TEORITIK}

Kurikulum Pendidikan Anak Usia Dini

Menurut NAEYC (National Association for the Education of Young Children) kurikulum merupakan suatu rencana yang meliputi ilmu disiplin, perkembangan, serta menyesuaikan dengan karakteristik setiap siswa dan disesuaikan dengan kebutuhan daerah dengan mengikuti perkembangan jaman sehingga sesuai dengan asas manfaatnya (Maryatun, 2014)

Berdasarkan teori di atas maka dapat disimpulkan bahwa, kurikulum merupakan payung besar yang dikembangkan oleh setiap lembaga, yang berisi tentang filosofi, pandangan, kepercayaan, cara belajar anak, materi pembelajaran, dan rancangan pembelajaran anak.

Pengembangan Kurikulum Pendidikan Anak Usia Dini

Menurut NAEYC Early

Childhood Program Standar terdapat

2 (dua) hal penting tentang kurikulum bagi anak usia dini yaitu, (1) Kegiatan pembelajaran diterapkan melalui bermain dan disesuaikan dengan kurikulum yang berpusat pada anak serta mendukung pembelajaran dan perkembangan baik estetika, kognitf, emosional, bahasa, fisik dan sosial, (2) berbagai konsep dan perkembangan dapat ditinjau dari hasil kurikulum (Sujiono, 2009). Penyampaian kurikulum oleh guru diharapkan dapat membantu dan menyediakan pengalaman belajar dalam mengembangkan potensi anak pada jenjang selanjutnya serta memberikan kesempatan pada anak untuk berkreatifitas, belajar secara mandiri dan berkelompok sesuai kebutuhan dan minat. 
Unit Studies Curriculum: Strategi Guru... Yunita, Ajeng, \& Mozes

\section{Unit Studies Curriculum}

Unit Studies Curriculum adalah kurikulum yang digunakan oleh Jungle School. Kurikulum ini dibuat oleh pengelola sekolah dari hasil observasi terhadap murid-murid yang bersekolah di Jungle School yang mempelajari tentang tema secara terstruktur dimulai dari huruf A hingga huruf $\mathrm{Z}$, dan juga memiliki tema mengenai hari-hari besar seperti natal, paskah. Dalam kurikulum Unit Studies terPada setiap tema terdapat fun fact and inspirational info, activitas ideas, dan craft ideas sebagai panduan bagi guru dalam menemukan ide-ide atau kegiatan yang baru.

\section{Strategi Pembelajaran Anak Usia Dini}

Tujuan Garis Besar Program Kegiatan Belajar TK adalah membantu meletakkan dasar kearah perkembangan sikap, pengetahuan, keterampilan, dan daya cipta yang diperlukan anak dalam beradaptasi dengan lingkungannya dan tumbuh kembang anak selanjutnya (Nurmaidah, 2015).

Adapun strategi pembelajaran pada anak usia dini ialah selalu mengedepankan aspek-aspek aktivitas bermain, bernyanyi (bergembira), dan bekerja dalam arti berkegiatan merupakan tiga ciri PAUD. Ketiga hal ini akan mengasah otak, kecerdasan, emosi, dan keterampilan fisik yang dilakukan dengan ceria, bebas, dan tanpa beban.
Numaidah (2015) menyatakan untuk melaksanakan proses pembelajaran di lembaga pendidikan TK sangat membutuhkan strategi pembelajaran yang: (1) aktif, yakni memfokuskan pada keaktifan dan keterampilan anak untuk berkegiatan, berlatih secara mandiri yang selaras dengan pola pikir dan emosi anak; dan (2) atraktif, yakni metode pembelajaran yang menarik, menyenangkan, tidak membosankan, kreatif, dan bervariasi, sehingga tidak membuat anak menjadi bosan saat belajar dan berlatih. Kedua proses pembelajaran diatas merupakan strategi yang sangat sesuai untuk diterapkan di lembaga pendidikan TK. Penelitian ini bertujuan untuk memahami strategi yang digunakan guru dalam implementasi Unit Studies Curriculum di Jungle School.

\section{METODE PENELITIAN}

Penelitian ini menggunakan metode kualitatif dengan jenis penelitian fenomenologis, yaitu penelitian yang digunakan untuk meneliti pada kondisi obyek yang alamiah (sebagai lawannya adalah eksperimen) dimana peneliti adalah sebagai instrumen kunci. Teknik pengumpulan data dilakukan secara triangulasi (gabungan), analisis data bersifat induktif, dan hasil penelitian kualitatif lebih menekankan makna dari generalisasi (Sugiyono, 2010).

Data diperoleh dari hasil observasi di dalam kelas dengan berpartisipasi selama proses 
pembelajaran hingga berakhirnya kegiatan. Subjek penelitian ini berjumlah 5 orang guru yaitu 4 orang guru preschool dan 1 orang guru kindergarten. Penelitian ini dilaksanakan di TK Jungle School.

\section{HASIL DAN PEMBAHASAN}

\section{Hasil Penelitian}

\section{Unit Studies Curriculum di Jungle School}

Kurikulum Unit Studies merupakan kurikulum yang dibuat sendiri oleh pengelola sekolah. Berdasarkan hasil observasi, kurikulum ini pada dasarnya sama dengan kurikulum pada umumnya yaitu berupa tema, akan tetapi Kurikulum Unit Studies menyediakan dan membahas tema berdasarkan abjad dari huruf A (alligator), B (bugs), C (camping), D (dinosaurus), $\mathrm{E}$ (eggs), F (farms), G (gardening), $\mathrm{H}$ (hot air balloons), I (gloos), J (jungle), $\mathrm{K}$ (koalas and kangaroos), $\mathrm{L}$ (lions, leopards, ect), M (music), N (nocturnal), O (ocean), P (pirates), Q (queen), $\mathrm{R}$ (robots), $\mathrm{S}$ (snakes), $\mathrm{T}$ (tools and tuilding), $\mathrm{U}$ (universe), $\mathrm{V}$ (vehicles), $\mathrm{W}$ (weather), $\mathrm{X}$ (xray and doctor), Y (yeehaw (wild west)), Z (zoo),

\section{Perencanaan Implementasi Unit Studies Curriculum di Jungle School}

Sebelum guru melaksanakan pembelajaran, guru mengembangkan kurikulum dengan membuat lesson plan yang disebut sebagai tahap perencanaan. Untuk mengetahui tahap-tahap perencanaan, penulis mengikuti proses perencanaan implementasi yang dilakukan di Jungle School. Secara umum perencanaan implementasi Unit Studies Curriculum pada setiap jenjang (cicak class, kus-kus class, tiger class, orang utan class, dan kindergarten) yang dibuat oleh guru memuat tahapan-tahapan pembelajaran yang sama, yaitu: Menyiapkan lesson plan sebagai panduan dalam menjalankan proses pembelajaran, Menyiapkan media pembelajaran, Menyiapkan bahan dan alat untuk membuat craft, Mempersiapkan games, Mempersiapkan cerita, Menyediakan beberapa permainan di kelas.

\section{Implementasi Unit Studies}

Curriculum di Jungle School

Implementasi Unit Studies Curriculum pada setiap jenjang memiliki tahapan yang sama secara umum dengan sekolah lain. Namun tahapan pembelajaran pada jenjang kindergarten dijalankan sedikit bebeda. Kegiatan dimulai dengan circle time, pembelajaran sains yang membahas tema sains pada minggu tersebut, serta rotasi time dimana setiap kelompok anak akan dibagi ketiap station yang ada yaitu station math dan literasi. Berikut adalah tahapan implementasi Unit Studies Curriculum yang dilakukan guruguru di Jungle School pada table 1. 
Unit Studies Curriculum: Strategi Guru... Yunita, Ajeng, \& Mozes

Tabel 1. Tahapan Implementasi

\begin{tabular}{|l|l|}
\hline No & $\begin{array}{l}\text { Tahapan Implementasi Unit Studies } \\
\text { Curriculum }\end{array}$ \\
\hline 1. & $\begin{array}{l}\text { Free Play Outside or Inside, kegiatan } \\
\text { bermain bebas di area aula (indoor) } \\
\text { maupun di area playground kecil } \\
\text { (outdoor). }\end{array}$ \\
\hline 2. & $\begin{array}{l}\text { Circle Time, kegiatan pembuka yang } \\
\text { dilakukan setiap guru di Jungle School. }\end{array}$ \\
\hline 3. & $\begin{array}{l}\text { Craft Time, kegiatan yang direncanakan } \\
\text { guru di dalam lesson plan. }\end{array}$ \\
\hline 4. & Snack Time \\
\hline 5. & $\begin{array}{l}\text { Free Play Outdoors, dilakukan oleh guru } \\
\text { dala bentuk bermain bebas pada pagi hari } \\
\text { yang mewajibkan anak-anak bermain di } \\
\text { area playground. }\end{array}$ \\
\hline 6. & $\begin{array}{l}\text { Circle Time, menyelesaikan pekerjaan } \\
\text { tangan yang belum selesai. }\end{array}$ \\
\hline 7. & $\begin{array}{l}\text { Potty Break and Story Time merupakan } \\
\text { kegiatan akhir membacakan cerita }\end{array}$ \\
\hline 8. & $\begin{array}{l}\text { Class Guide Play, anak bermain bebas } \\
\text { sambil menunggu orang tua menjemput }\end{array}$ \\
\hline Strategi Guru di Jungle School \\
Melalui Bermain
\end{tabular}

Dari tahapan pembelajaran yang telah dijalankan, guru-guru di Jungle School juga mempunyai beberapa strategi khusus dalam kegiatan belajar yang sesuai dengan tema namun tidak mengikuti LKS. Tema dijalankan sesuai dengan abjad dari huruf A-Z. Sehingga guru dapat mengajarkan anak tentang abjad secara berurutan, bentuk, bunyi, dan beberapa kata dengan awalan huruf tersebut melalui games teka-teki, flash card, rainbow time, dan games lainnya. Guru-guru juga menggunakan beberapa strategi seperti bermain melalui permainan indoor dan outdoor, melalui alam, menggunakan barang bekas, dan bermain menggunakan craft project.

\section{Strategi Bermain Permainan Indoor dan Outdoor}

Bermain permainan indoor dan outdoor menjadi salah satu strategi pembelajaran yang digunakan setiap guru di Jungle School sehingga anak merasa senang dalam mengikuti kegiatan belajar. Dari hasil pengamatan bermain indoor dijalankan setiap guru selama 1 jam dari pukul 08.00-09.00 WIB di area aula bersama anak-anak dan guruguru dari kelas lain. Guru-guru telah membuat beberapa spot berupa spot balok, boneka, rumah-rumahan, mobil-mobilan, dan spot jungle café. Anak-anak diberikan kebebasan dalam bermain dan guru-guru diharuskan terlibat dalam bermain, bercerita, atau melakukan beberapa hal lainnya seperti membantu anakanak merapikan mainan, dll.

Berdasarkan wawancara, kegiatan ini disediakan sebagai pijakan awal pembelajaran yang membantu anak membangun minat dan perasaan senang sebelum mengikuti kegiatan di kelas. Menurut guru preschool kegiatan bermain bebas membantu anak-anak dalam melatih jiwa sosialisasinya. Sedangkan menurut guru kindergarten permainan indoor sebagai pijakan awal agar anak semangat tetapi juga membuat anak berkreasi dengan membuat peraturan dan games yang akan dimainkan, anak juga dapat mengembangkan kemampuan berbahasa dan memperbanyak kosa-kata dengan cara berkomunikasi dengan temantemannya.

GD: Jadi pinjakan awal bermain bebas itu sebenarnya bertujuan untuk mempersiapkan anak terlebih dahulu 
agar anak aktif dan siap mengikuti pembelajaran di kelas.

Permainan outdoor dilakukan anak di playground. Selama permainan berlangsung, terlihat guruguru juga turut berpartisipasi di dalamnya. Contohnya saat anak-anak bermain permainan jumping, guru juga terlihat ikut bermain bersamasama dan mengikuti aturan yang ada yaitu ikut berbaris menunggu giliran. Tidak hanya itu, anak-anak juga bermain games yang dibuat sendiri seperti games freez take dan beberapa games lainnya yang melibatkan guru di dalamnya untuk melatih dan mengembangkan gross motor hal ini sesuai dengan hasil wawancara;

GD: Untuk permainan outdoor sendiri karena berada diluar jadi lebih menyasar ke gross motor skill, anak-anak jadi bisa berlarian menangkap teman-teman, bahkan membuat peraturan sendiri ketika bermain. Sedangkan kalau permainan indoor anak-anak lebih tenang. Tidak hanya itu permainan outdoor mengajarkan anak untuk belajar mengikuti peraturan yang dibuat, untuk membantu anak memahami dan menerapkan guru juga ikut menaati peraturan ketika bermain bersama murid.

\section{Strategi Bermain Melalui Alam}

Hasil pengamatan, bermain melalui alam merupakan strategi guru dalam menyampaikan materi secara nyata agar mempermudah anak memahaminya. Berdasarkan wawancara, pengelola sekolah menambahkan bahwa dari pengalaman anak akan lebih paham dan mudah mengingat apa yang mereka dapatkan.

PS: Karena memang caranya anak itu bermain lewat salah, lewat eksperimen, lewat pengalaman kalau hanya kita kasih mereka teori belum ada aplikasian langsung di hidupnya ya tetap mereka belum paham.

Guru juga mengatakan bahwa dari kegiatan tersebut, anak bisa merasakan, melihat, sehingga semua indra terpakai, anak juga lebih mudah menyerap setiap penjelasan yang diberikan.

GD: Anak bisa belajar langsung dari yang aslinya gk hanya gambar, jadi merasakan melihat semua indra terpakai untuk belajar itu. Anak lebih bisa menyerap karna setiap anak kan belajarnya konkrit.

\section{Strategi Bermain Menggunakan Barang Bekas}

Hasil observasi di Jungle School menunjukkan barang bekas dimanfaatkan oleh guru-guru untuk permainan anak pada area outdoor dan indoor. Area outdoor, barang bekas seperti kayu untuk pondok dan rumah pohon, ban bekas untuk ayunan, karet bekas untuk permainan lompat, panci dan wajan bekas untuk permainan musik, dll. Sedangkan area indoor, guru menggunakan barang bekas yang terdapat di dalam kelas, seperti bola kertas dari koran untuk bermain lempar bola, sedotan bekas untuk bermain lempar sedotan ke 
Unit Studies Curriculum: Strategi Guru... Yunita, Ajeng, \& Mozes

dalam wadah, mengisi wadah dengan air menggunakan botol bekas, dll.

Dari hasil wawancara, menurut guru pemanfaatan barang bekas yang dilakukan di sekolah sesuai dengan lingkungan sekolah yaitu sekolah alam. Guru menggunakan barang bekas dalam mengajari anak untuk lebih menyayangi, menjaga, merawat bumi dan menanamkan konsep 3R "reduce, reuse, dan recycle".

GD: Dalam sekolah alam kita mengajarkan anak untuk lebih mencintai bumi, dengan cara anak diberi pengetahuan tentang reduce, reuse dan recycle, seperti membuat kreatifitas dari barang bekas, lebih mengurangi penggunaan barangbarang berbahan dasar plastik serta anak diajak untuk menggunakan kembali barang-barang yang masih bisa terpakai seperti plastik bersih untuk digunakan kembali.

\section{Strategi Bermain Menggunakan Grup Project Atau Individu Project (Craft)}

Bermain menggunakan grup project atau individu project (craft) juga merupakan kegiatan bermain yang disediakan guru-guru di Jungle School. Pada Grup project guru mengajak anak-anak untuk membuat craft secara berkelompok pada hari senin. Setelah jadi, craft diletakan di tempat yang luas dalam kelas sehingga anak-anak dapat memainkannya secara bersama-sama. Sedangkan individu project ini dimainkan secara bersama-sama tetapi menggunakan craft masing- masing anak, karena setiap anak memiliki craft sendiri-sendiri.

Dari hasil observasi, bermain menggunakan grup dan individu project biasa digunakan setelah guru membahas tentang tema. Di preschool setiap kelas akan membuat grup project lalu diletakkan di area indoor (aula) sehingga dapat dimainkan secara bersama-sama dengan kelas lain. Sedangkan di kindergarten grup project akan diletakkan di kelas sehingga dapat menghias kelas maupun dapat dimainkan oleh anak-anak. Berdasarkan wawancara kegiatan ini bertujuan untuk mengajarkan anak bahwa craft yang dibuat bermanfaat menjadi suatu permainan maupun untuk memperindah kelas.

GD: Jadi mereka, yang mereka bikin itu berguna sebenarnya sih ada yang hanya untuk di pajang yang mereka buat, trus kadang kayak dulu kan kemarin bikin bola dari kertas trus kita pakai ya biar apa ya, biar mereka tau bahwa apa yang mereka buat itu sebenarnya bisa bermanfaat juga, mereka bisa bermain dari apa yang sudah mereka bikin.

\section{Pembahasan}

\section{Perencanaan Unit Studies Curriculum}

Dari hasil observasi, sebelum pelaksanaan pembelajaran dijalankan, guru akan membuat lesson plan yang berisi kegiatan sesuai dengan kesiapannya maksimal 1 hari sebelum kegiatan berlangsung. 
Guru kelas yang bersangkutan membuat lesson plan di lingkungan sekolah agar para guru dapat saling berbagi ide dan masukan untuk pengembangan pembelajaran di kelas. Persiapan lesson plan sudah termasuk media pembelajaran, craft, cerita, games yang disesuaikan dengan kebutuhan setiap jenjang. Hal ini sesuai dengan pendapat Sujiono (2009)bahwa kurikulum merupakan suatu penerapan yang sangat terencana sehingga perencanaan implementasi Unit Studies di Jungle School merupakan bagian yang penting dilakukan sebelum pelaksanaan pembelajaran oleh guru.

\section{Implementasi Unit Studies Curriculum oleh Guru Preschool (cicak class, kus-kus class, tiger class, orang utan class) dan Kindergarten}

Secara umum implementasi yang dilakukan guru-guru preschool dan kindergarten di Jungle School yaitu melalui bermain dibuat sesuai dengan tema, topik pembelajaran maupun tingkat usia anak. Bermain merupakan kegiatan yang menyenangkan dan bersemangat bagi anak (Fadillah, 2016). Menurut Hartley (dalam Mahardika, 2014) bermain adalah unsur penting sebagai sarana komunikasi, sosialisasi, anak dapat mengeksplor dunia, memahami diri sendiri, belajar memcahkan masalah, dan melatih setiap keerampilan yang ada. Setiap guru memiliki caranya masing-masing dalam menjalankan kegiatan belajar mengajar. Berdasarkan hasil wawancara, penerapan kurikulum di Jungle School banyak menyampaikan materi melalui bermain karena anakanak identik dengan bermain. Melalui bermain mereka belajar banyak hal, mengembangkan setiap aspek, mencapai rasa senang dan nyaman ketika mengikuti proses pembelajaran. Guru yakin dengan bermain anak belajar melalui pengalaman, bersosialisasi, berkomunikasi, berkreasi membuat games bersama teman-teman, serta membuat peraturan.

Berdasarkan hasil penelitian guru cicak, tiger dan kuskus kelas menjalankan kegiatan circle, guru mengajak anak melakukan kegiatan yoga yang bertujuan untuk melatih gross motor dan melibatkan anak langsung dengan alam sekitar melalui games "rocks, hindden paper" dan beberapa games lainnya. Melibatkan anak secara langsung dengan alam merupakan alternative yang sangat penting karena anak memiliki kesempatan lebih banyak dalam mengembangkan aspek-aspek yang ada.

Proses pembelajaran circle time diisi guru dengan mengajarkan anak belajar membaca permulaan, seperti mengenalkan dan mengingatkan huruf serta bunyi dari huruf tersebut, dan menghubungkan bunyi tersebut. Menurut Anderson (dalam Astuti, 2016) mengemukakan bahwa kemampuan membaca awal adalah kegiatan membaca yang diberikan 
Unit Studies Curriculum: Strategi Guru... Yunita, Ajeng, \& Mozes

secara terpadu yaitu mengaitkan keterampilan antara pengenalanan huruf dan kata, menghubungkan dan membunyikan. Membaca permulaan ini dilakukan oleh guru B dan C, namun dengan perlakuan atau cara yang berbeda seperti menuliskan di papan dan penggunaan media huruf. Di kindergarten guru mengajarkan anak tentang math, science, dan literacy sebagai bekal saat anak berada di bangku Sekolah Dasar, melalui games dan objek nyata. Kesiapan untuk memasuki sekolah dasar lebih menitikberatkan pada aspek koginitif dan literasi seperti membaca, menulis, dan berhitung (Syarfina, Yetti, \& Fridani, 2018).

Berdasarkan wawancara pembelajaran konsep math, science, dan literacy anak akan mudah dipahami dan merasakan secara nyata saat disampaikan melalui games dan menggunakan benda real. Membantu anak mengembangkan aspek bahasa, guru cicak kelas dan kindergarten juga menyediakan waktu membaca buku bagi setiap anak.

Sedangkan pemberian waktu membaca buku bagi guru cicak, bertujuan untuk membantu anak menyalurkan imajinasi, belajar berbicara, dan menceritakan kepada orang lain sesuai dengan gambar yang dilihat tanpa mengikuti teks pada buku cerita. Hal ini serupa dengan pendapat Nurgiyantoro (dalam Afnida, Fakhriah, \& Fitriani, 2016) gambar bertujuan untuk memperkaya kosa kata, membuat karakter secara nyata, serta sebagai imajinasi dan daya tangkap terhadap teks yang masih terbatas.

\section{Strategi Guru di Jungle School Melalui Bermain}

Berdasarkan hasil penelitian, dalam menjalankan proses pembelajaran yang menarik, menyenangkan, dan nyaman, guru menjalankan kegiatan melalui bermain. Beberapa kegiatan bermain dilakukan sesuai dengan tema pembelajaran dan beberapa dilakukan sesuai dengan kebutuhan anak. Menurut Dockett dan Fleer (dalam Sujiono, 2009) pengetahuan yang dapat mengembangkan kemampuan diri anak bisa didapatkan melalui proses bermain, karena bermain merupakan kebutuhan bagi anak. Kegiatan bermain yang diberikan bermacam-macam dari permainan indoor dan outdoor, bermain melalui alam, bermain menggunakan bahan bekas dan bermain dengan project yang telah dibuat.

Guru juga memberikan permainan outdoor bagi setiap anak dengan bebasnya. Pada permainan outdoor anak lebih banyak bermain menggunakan fisik yang melibatkan energi sangat banyak seperti memanjat, melompat, berlari, bergelantungan, bermain bola, yang menggunakan koordinasi tubuh. Permainan yang melibatkan energi ini membantu anak untuk menjadi penjelajah yang aktif dalam lingkungannya, membantu anak dalam mengendalikan tubuh, dan 
membantu anak dalam mengkoordinasikan setiap bagian tubuh yang berbeda (Sujiono, 2009).

Belajar melalui alam sekitar membatu anak dalam memahami materi dengan baik, anak juga belajar hal-hal baru secara alami dari pengalaman yang diperoleh. Bermain menggunakan barang bekas dan craft juga digunakan untuk mengajarkan anak tentang merawat, melindungi dan menyanyangi bumi, anak juga belajar bahwa craft yang telah dibuat dapat bermanfaat selain menjadi permainan tetapi juga dalam menghias kelas.

\section{KESIMPULAN}

Berdasarkan hasil penelitian dan pembahasan dapat disimpulkan bahwa strategi iplementasi kurikulum di Jungle School diterapkan melalui bermain. Pembelajaran tidak mengikuti LKS, tema diberikan sesuai abjad dari A-Z, yang bertujuan untuk mengajarkan anak tentang abjad secara berurutan, bentuk, bunyi serta beberapa kata sesuai abjad, yang disampaikan susai usia dan topik pembelajaran melalui dengan penggunaan media dari alam, barang bekas, dll, agar anak mudah memahani, merasa senang dan nyaman dalam mengikuti pembelajaran, anak juga belajar banyak hal melalui pengalaman yang di dapat dengan melihat dan menyentuh objek nyata dialam, dan membantu anak memahami bagaimana cara melindungi dan merawat bumi dengan penggunaan barang bekas serta belajar menghargai craft yang dibuat.

\section{DAFTAR PUSTAKA}

Afnida, M., Fakhriah, \& Fitriani, D. (2016). Penggunaan Buku Cerita Bergambar dalam Pengembangan Bahasa Anak pada TK A di Banda Aceh. Jurnal Ilmiah Mahasiswa Pendidikan Anak Usia DIni, 1(1), 53-59.

Astuti, S. K. (2016). Pelaksanaan Pembelajaran Membaca Permulaan DI Kelompok A Taman Kanakkanak Aba Pendowo. Jurnal Pendidikan Guru Pendidikan Anak Usia Dini, (3), 194-204.

Cholimah, N. (2012). Pengembangan Kurikulum PAUD Berdasarkan Permen 58 Tahun 2009.

Fadillah. (2016). Edutaiment Pendidikan Anak Usia Dini Menciptakan Pembelajaran Menarik, Kreatif, dan Menyenangkan. Jakarta: Pranada Media Group.

Maryatun, I. B. (2014). Konsep Pengembangan Kurikulum PAUD.

Nurmaidah. (2015). Strategi Pembelajaran Anak Usia Dini. Jurnal Al-Afkar, VIII, 1-28.

Sugiyono. (2010). Statistika untuk Penelitian. Bandung: Alfabeta.

Sujiono, Y. N. (2009). Konsep Dasar Pendidikan Anak Usia Dini. Jakarta: Indeks.

Syarfina, Yetti, E., \& Fridani, L. (2018). Pemahaman Guru Prasekolah Rudhatul Athfal Tentang KEsiapan Sekolah Anak. Jurnal Pendidikan Usia Dini, 12, 153-163. https://doi.org/https://doi.org/https: //doi.org/10.21009//JPUD.121.13

Winarso, W. (2017). Dasar Pengembangan Kurikulum Sekolah, (January 2015). 